\title{
A Research Note Sugars of Pearl Millet [Pennisetum americanum (L.) Leeke] Grains
}

\author{
V. SUBRAMANIAN, R. JAMBUNATHAN and S. SURYAPRAKASH
}

\section{ABSTRACT}

The sugars in the grains of nine pearl millet cultivars were fractionated through a Biogel column. Five different sugars "(stachyose, raffinose, sucrose, glucose, and fructose) were identified. Sucrose was predominant in all the cultivars. Raffinose content was high as compared to other cereals, and maltose was absent.

\section{INTRODUCTION}

PEARL MILLET [Pennisetum americanum (L.) Leeke] is an important food grain and is one of the major souce of calories and protein for a large segment of population in the semi-arid tropical regions of India and Africa. Very little information is available on the biochemical and nutritional qualities of millet grains. At the International Crops Research Institute for the Semi-Arid Tropics (ICRISAT), studies on the physicochemical characteristics of millet flour and their relationship with roti-making characteristics are being investigated. Sugars may be one of the factors imparting taste and flavor to the food products made from millet grain. Hence the present study was undertaken to determine the sugar content and composition of nine millet cultivars.

\section{MATERIALS \& METHODS}

Pearl millet samples

Threc local cultivars of Rajasthan-Alot, Chadi and Sulkhania, and the four hybrids PHB-14, BJ-104, ICH-105, and ICH-118 were grown at our Center during the rainy season fo 1978. Two lines, JB-483-1 and JB-12-3 1 AXJN5, were received from Jobner Agricultural College, Rajasthan. The mature grains of these nine cultivars were separately ground to a meal in a Udy cyclone mill to pass through a 60 -mesh sieve and were defatted using n-hexane in a Soxhlet apparatus.

\section{Sugar extraction}

The defatted millet meals were extracted with $80 \%$ ethanol for $5 \mathrm{hr}$ in a Goldfisch apparatus. The quantity of soluble sugars in the extracts was estimated by the phenol-sulphuric acid method of Dubois et al. (1956).

\section{Column chromatography}

A slightly modified procedure of John et al. (1969) as described earlier (Subramanian et al., 1980) was used for separating the sugars. The individual sugar peaks were identified by the independent application of known quantities of each of the standard sugars (stachyose, raffinose, sucrose, glucose and fructose) and the sugars were eluted through the column. A mixture of these sugar solutions was also applied and eluted through the column in order to compare the elution profiles obtained with individual sugars. The sugars in the samples were identified by reference to the elution patterns of standard sugars. For quantitative estimation of individual sugars, each fraction eluting from the column was individ-

All authors are affiliated with the International Crops Research Institute for the Semi-Arid Tropics, (ICRISAT), ICRISAT Patancheru P.O. 502 324, A.P., India. ually analyzed. The absorbance of each of the fractions was plotted and the area of the peak was compared with the area of their respective standards.

Thin-layer chromatography

Sugars were also separated on thin-layer chromatography (TLC) plates, prepared using an aqueous silica gel slurry $(40 \mathrm{~g} / 100 \mathrm{ml})$. A solvent system consisting of chloroform, acetic acid and water $(3.0: 3.5: 0.5, v / v)$ was used as described by De Stefanis and Ponte (1968). The sugar spots were detected using the diphenylamineaniline reagent.

\section{RESULTS \& DISCUSSION}

THE TOTAL SUGARS content in the grains of the nine millet cultivars ranged from $2.16-2.78 \%$ (Table 1). Fussel and Pearson (1978) reported that the soluble sugars content of millet grain at final harvest was $2.4 \%$. Fractionation of soluble sugars on Biogel column revealed the presence of five sugars in the extracts. Stachyose, raffinose, and sucrose were eluted from the Biogel column in that order, followed by glucose and fructose, which were eluted as a single peak. The presence of these five sugars in the ethanolic extracts of millet meals was also confirmed by the TLC method by comparison with the respective standards. In addition, two other unidentified spots (traces) of low molecular weight sugars were observed by the TLC method but were not detected when the sugar extracts were eluted through the column. For one of the samples (BJ-104), the fractions of individual sugar peaks eluted from the column were pooled. Each of the pooled sugar fractions was evaporated in vacuo and dissolved in a minimum quantity of water and then separated on TLC plates along with their respective standards. The identity of the individual sugars in the fractions was confirmed by this procedure. The pooled fourth fraction showed the presence of both glucose and fructose by this procedure as well.

Sucrose is the predominant sugar in the millet grains and ranged from $60-68 \%$ of the total sugars in the nine samples (Table1). As compared to sorghum, the proportion of sucrose in millet was low (Subramanian et al., 1980). Sucrose has been reported to be one of the major components of sugar in wheat (Koch et al., 1951). Raffinose content in millet is higher than in other cereals, comprising nearly $25 \%$ of total sugars. The presence of raffinose in wheat has also been reported by MacArthur and D'Appolonia (1979).

The amount of stachyose in millet ranged from $0.06-$ $0.13 \%$ in the samples which accounts for $2.4-4.7 \%$ of total sugars in the grain. The quantity of glucose and fructose in millet ranged from $3.2-6.3 \%$ of the total sugar content. Maltose was not detected in the millet samples. The separation of sugar extracts on TLC plate also did not show the presence of maltose. This was further verified by TLC of a mixture containing sugar extract of BJ104 and reagent grade maltose. The concentration of maltose was approximately equivalent to one hundredth of the concentration of sucrose in the sugar extracts. While maltose was not detected in the sugar extract of sample, it was clearly visible in the sugar extracts containing maltose. Though maltose was reported to be present in small quantities $(0.05 \%)$ in sugary sorghum (Watson and Hirata, 
Table 1-Soluble sugars composition of pearl millet grains ${ }^{\mathrm{a}}$

\begin{tabular}{|c|c|c|c|c|c|}
\hline Cultivar & $\begin{array}{c}\text { Total solu- } \\
\text { ble sugars } \\
\text { (\%) }\end{array}$ & $\begin{array}{c}\text { Stachyose } \\
(\%)\end{array}$ & $\begin{array}{c}\text { Raffinose } \\
(\%)\end{array}$ & $\begin{array}{c}\text { Sucrose } \\
(\%)\end{array}$ & $\begin{array}{c}\text { Glucose + } \\
\text { Fructose } \\
(\%)\end{array}$ \\
\hline Alot & 2.67 & $0.09(3.2)$ & $0.67(25.0)$ & $1.82(68.2)$ & $0.10(3.6)$ \\
\hline Chadi & 2.67 & $0.13(4.7)$ & $0.84(31.3)$ & $1.60(59.9)$ & $0.11(4.0)$ \\
\hline Sulkhania & 2.57 & $0.10(3.7)$ & $0.65(25.3)$ & $1.66(64.6)$ & $0.16(6.3)$ \\
\hline PHB-14 & 2.56 & $0.06(2.4)$ & $0.65(25.2)$ & $1.74\langle 68.1\rangle$ & $0.11(4.3)$ \\
\hline BJ-104 & 2.16 & $0.08(3.5)$ & $0.67(31.1)$ & $1.32(61.2)$ & $0.09(4.3)$ \\
\hline $\mathrm{ICH}-105$ & 2.72 & $0.10(3.8)$ & $0.81(29.6)$ & $1.72(63.3)$ & $0.09(3.2)$ \\
\hline $1 \mathrm{CH}-118$ & 2.59 & $0.08(3.2)$ & $0.66(25.4)$ & $1.76(68.1)$ & $0.08(3.2)$ \\
\hline JB-483-1 & 2.78 & $0.10(3.5)$ & $0.81(29.3)$ & $1.75(63.0\rangle)$ & $0.12(4.3)$ \\
\hline JB-12-3. 1 AXJN5 & 2.32 & $0.10(4.1)$ & $0.68(29.3)$ & $1.44(62.1)$ & $0.11(4.5)$ \\
\hline
\end{tabular}

Moisture-free basis; each value represents the mean of two independent determinations. Figures in parenthesis are expressed as per cent of total sugars.

Table 2-Sugar composition of wheat, maize, barlev, oat, and sorghum $(g / 100 \mathrm{~g}$ sample)

\begin{tabular}{lcccccc}
\hline Cereal & Raffinose & Sucrose & Maltose & Fructose & Glucose & References \\
\hline Wheat flour & $0.05-0.43$ & $0.16-0.60$ & $0.07-0.09$ & $0.02-0.03$ & $0.04-0.06$ & MacArthur \& D'Appolonia (1979) \\
Maize & $0.20-0.30$ & $0.70-1.25$ & - & $0.20-0.26$ & 0.03 & Cerning (1970) \\
Barley & $0.14-0.83$ & $0.34-1.69$ & 0.14 & $0.03-0.16$ & $0.02-0.09$ & Kent (1975) \\
Oat flour & $0.16-0.26$ & $0.40-0.63$ & $0.01-0.03$ & $0.02-0.05$ & $0.06-0.07$ & MacArthur \& D'Appolonia (1979) \\
Sorghum & $0.10-0.39$ & $0.92-3.90$ & - & $0.06-0.74^{\mathrm{a}}$ & Subramanian et al. (1980) \\
\hline
\end{tabular}

a Fructose + glucose

1960), its absence has been reported in proso and foxtail millets (Becker and Lorenz, 1978).

The sugar composition of various cereals is given in Table 2. Sucrose forms the major component of sugars in all the cereals. Raffinose content is higher in barley, similar to pearl millet. The quantity of maltose is low in cereals. Glucose and fructose contents showed a wide variation among the cereals.

\section{REFERENCES}

Becker, R. and Lorenz, K. 1978. Saccharides in proso and foxtail millets. J. Food Sci. 43: 1412.

Cerning. J. 1970. Contribution a l'étudé de l'evolution de la composition glucidique des céréals aucour de leur maturation: mais. blé, orge. These de Doctorat de l'université de Lille No. 80 . De Stefanis, V.S. and Ponte, J.G. 1968. Separation of sugars by thin-layer chromatography. J. Chromatog. 34: 116.

Dubois, M., Gilles, K.A., Hamilton, J.K., Rebers, P.A., and Smith, F. 1956. Colorimetric method for determination of sugars and related substances. Anal. Chem. 28; 350.

Fussel, L.K. and Pearson, C.J. 1978. Course of grain development and its relationship to black region appearance in Pennisetum americanum. Field Crops Research 1:21

John, M., Gotz, T., and Dellweg, H. 1969. Quantitative chromatography of homologous glucose oligomers and other saccharides using poly acrylamide gel. J. Chromatog. 42: 476.

Kent, N.L. 1975. "Technology of Cereals with Special Reference to Wheat,"p. 49. Pergamon Press, Oxford.

Koch, R.B., Geddes, W.F., and Smith, F. 1951. The carbohydrate of the gramineae: 1 . The sugars of the flour of wheat (Triticum of the gramineae: 1. The sugars
vulgare). Cereal Chem. 28: 424 .

MacArthur, L.A. and D'Appolonia, B.L. 1979. Comparison of Oat and Wheat Carbohy drates. Cereal Chem. 56:455.

Subramanian. V.. Jambunathan, R., and Suryaprakash, S. 1980. Note on soluble sugars of Sorghum bicolor (L.) Moench. Cereal Chem. 57: 440.

Watson, S.A. and Hirata, Y. 1960. Carbohydrates in grain sorghum kernels. Sorghum Newsletter 3:7. Ms received $11 / 20 / 80$; accepted $3 / 31 / 81$.

Journal article no. 160 by the International Crops Research Institute for the Semi-Arid Tropics.

The authors are thankful to Drs. K. Anand Kumar and S. Appa Rao of ICRISAT and Dr. Shama, Scientist, Agricultural College. Jobner for providing the samples. 